Original Research Paper

\title{
Experimental Evaluation of the Raking Energy in Damping System of Steel Stud Partition Walls
}

\author{
Salah Amer, Sameer Hamoush and Taher M. Abu-Lebdeh \\ Department of Civil, Architectural and Environmental Engineering, \\ North Carolina A\&T State University, Greensboro, NC, USA
}

\author{
Article history \\ Received: 28-07-2015 \\ Revised: 14-09-2015 \\ Accepted: 08-10-2015 \\ Corresponding Author: \\ Taher M. Abu-Lebdeh \\ Department of Civil, Architectural \\ and Environmental Engineering, \\ North Carolina A\&T State \\ University, Greensboro, NC, USA \\ Email: taher@ncat.edu
}

\begin{abstract}
Nonstructural partition walls are usually specified based on the best practice without any structural design calculations. However, given the likely severe earthquake damage to nonstructural components and the substantial cost of repair to such components, it is imperative that we develop an understanding of the seismic response of the nonstructural partition walls when subjected to earthquake loading conditions. The main objective of this investigation is to experimentally evaluate the effectiveness of utilizing low cost damping protection system in improving the seismic performance of the steel stud partition walls. Nine full scale wall specimens of $4.0 \mathrm{ft}$ wide and $8.0 \mathrm{ft}$ high were divided into three groups of different damping systems. Three specimens were constructed with Single Damping System (SDS), three specimens with Double Damping System (DDS) and three wall specimens with No-Damping System (NDS) in order to have a basis for comparison. Wall specimens were subjected to in-plane cyclic loadings for drifts ranging from 0.25 " to 2.75 " (0.3 to $3 \%$ drifts of wall height). Seismic evaluation included both ductility capacity and energy dissipation. Test results revealed that, although, damping does not influence wall capacity, it improves ductility and delays damages to later drifts. Incorporating damping system increased wind load capacity and seismic load capacity by 50 and $700 \%$ respectively. Also, ductility factors and cumulated dissipated energy increased by 40 and $112 \%$ respectively for SDS and 83 and $137 \%$ for DDS. The research study concluded that the low cost protection damping system significantly improved the seismic performance of the partition wall systems.
\end{abstract}

Keywords: Partition Walls, Seismic Loadings, Damping Grommets, Ductility Factor, Energy Dissipated

\section{Introduction}

In the last two decades the world suffered an increase in major earthquakes hazards. The National Earthquake Hazards Reduction Program (NEHRP) and the US Geological Survey (USGS) recorded one hundred and ten (110) earthquakes in 2014 with a major magnitude of 8.2 occur in Chile and forty two (42) earthquakes in the first five months of the year 2015 with a major magnitude of 7.8 struck Nepal causing hundreds of thousands of lives and hundreds billions of US dollars in losses. Extensive studies have been conducted to understand the behavior of structures subjected to seismic loading. As a results of these investigations, it was reported that the majority of the earthquake damages were in the non-structural components such as plumping connections, air-condition and heating ducts, partition walls and building contents. For instance, Whittaker and Soong (2003) show that $50 \%$ of the $\$ 18.5$ billion losses caused by the 1994 Northridge earthquake was due to non-structural damages. Ryan et al. (2011) reported that the cost of repair/replacement of non-structural components due to earthquakes could reach about $75 \%$ of the total estimated cost of buildings. Great part of this cost is due to partition walls which includes direct cost to repair or replace the walls and indirect cost as falling partition walls damages building contents and devices.

Given the high cost of repair of the nonstructural components, it is essential that we develop better understanding of the seismic behavior of nonstructural wall systems, including partition walls. Several studies were performed in order to improve the seismic response 
of the partition walls. Some of these studies were conducted in the field to investigate the seismic behavior of existing buildings (Nagarajaiah and Xiaohong, 2000; Mokha et al., 1996). For example, Nagarajaiah and Xiaohong (2000) conducted study at University of South California to investigate the response of base-isolated hospital building in Northridge earthquake area. Their work demonstrated the superiority of the base-isolated structures in comparison to the fixed footing structures. Mokha et al. (1996) investigated the seismic isolation of historic building. Other studies were conducted in the lab simulating earthquakes using shake tables or cyclic loading equipment in order to investigate the seismic behavior of the partition walls subjected to different designed seismic loading. Singh et al. (2000) discussed the use of active controlled mass damper to balance structure drift. Dyke et al. (1996) investigated magnetorheological dampers as seismic response reduction. Lee et al. (2007) performed cyclic loading tests on four full scale partition wall specimens with $12.0 \mathrm{ft}$ long and $8.0 \mathrm{ft}$ high to observe seismic damages and to investigate the effect of openings such as doors and windows on the seismic response of the walls. They found that no serious damages occur up to story drift of $1 \%$, however, damages at wall boundaries was observed above $1 \%$ drift. They reported that at $2 \%$ drift, the repair cost could reach the initial cost of the wall. The work presented in this paper is part of an extensive investigation (www.nees-nonstructural.org) funded by the National Science Foundation (NSF) and Network for Earthquake Engineering Simulation (NEES) and conducted at Nevada University in Reno, Nevada (UR) in March 2013 and at University of New York at Buffalo (UB) in 2009. In this investigation, full scale two-story building (60 ft. long, $12 \mathrm{ft}$ wide and 23 $\mathrm{ft}$ in height) was subjected to designed earthquake simulation using large scale shake table. The building contains different types of partition walls fixation, plumping connection, electrical connection, suspended ceiling and furnished with disks, books, computers and shelves to analyze the damage propagation. Figure 1 shows the shake table test for the two-story building. Also, under the same testing program, partition wall tests were conducted at University of New York at Buffalo (UB) in 2009 for in-plane and out-plane loading on 50 full scale (12.0 ft long and $8.0 \mathrm{ft}$ high) wall specimens to investigate the effect of seismic inplane (36 specimens) and out of-plane (14 specimens) loadings and to analyze walls' performance and fragility during earthquake incidence. Figure 2 shows the UB Partition wall tests.

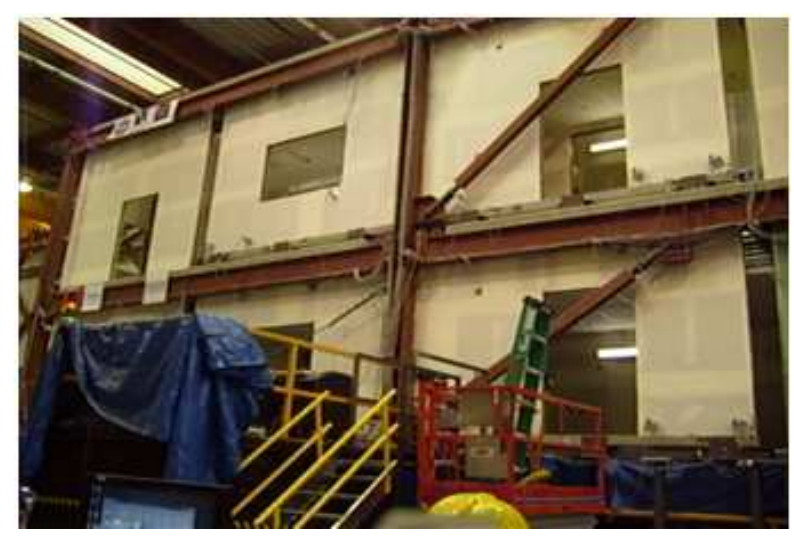

Fig. 1. Shake table test for the two-story building
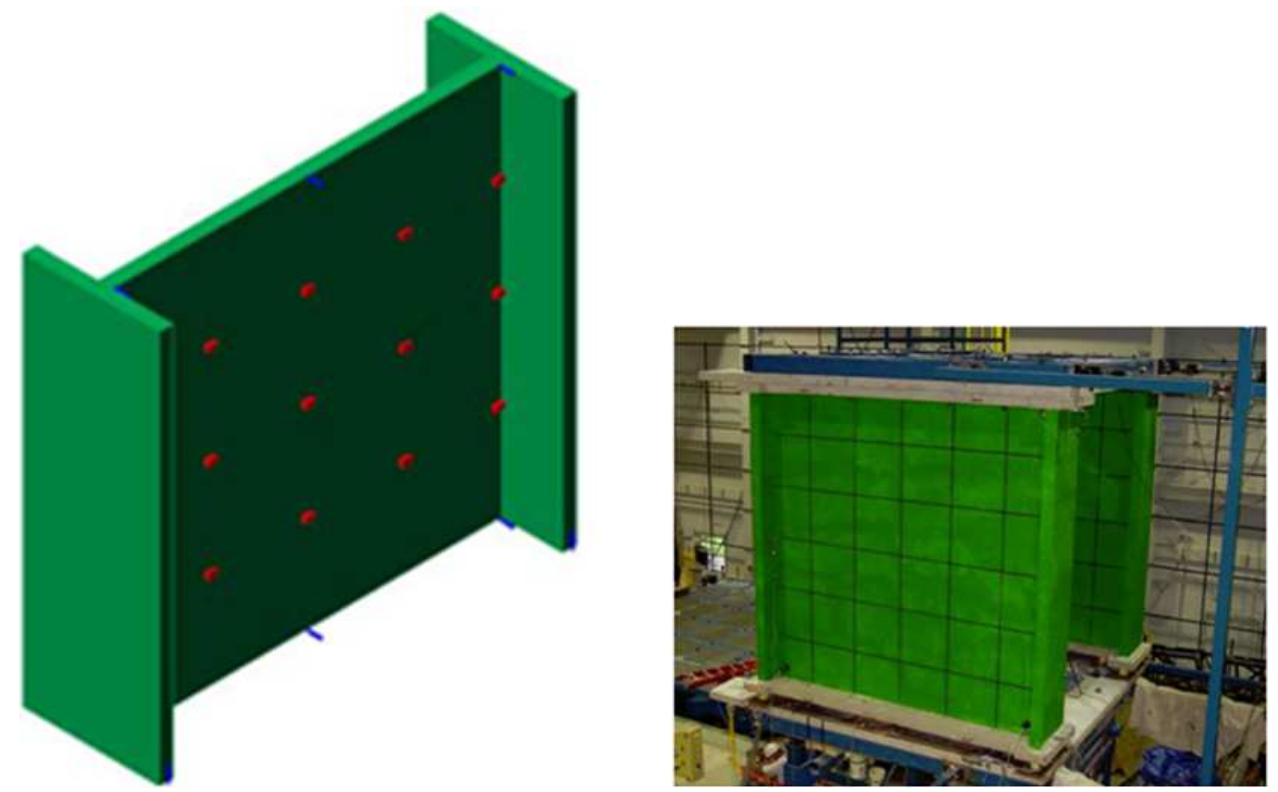

Fig. 2. UB Partition wall test 
The main objective of the study presented in this paper is to perform energy evaluation of steel studs partition walls constructed with three different damping systems and subjected to cyclic loadings. The overall objectives of the study are: (1) Investigate the capacity and performance of partition walls with different damping systems when subjected to wind or seismic loadings; and (2) Measure the dissipated energy and ductility of the partition walls of different damping systems.

\section{Experimental Program}

The experimental plan is designed to investigate the efficiency of using rubber grommets as damping system to steel stud partition walls subjected to cyclic loadings. Efficiency is determined according to partition wall response to cyclic loadings, wall capacity and absorbed energy. The test protocol considers in-plane cyclic loadings with $3 \%$ maximum deferential drift at the top of the partition wall. The experimental program tested nine full scale specimens of $4.0 \mathrm{ft}$ (width) and $8.0 \mathrm{ft}$ high as shown in Fig. 3.

Specimens were divided into three groups (Table 1): Three specimens of group-1were tested with NoDamping System (NDS) as control test; three walls of group-2 were tested with Single Damping System (SDS), in which the damping grommets were installed at the supporting points of one side of the bottom track; and group-3 was tested using Double Damping System
(DDS) where the damping grommet installed on and under the bottom track at the supporting points. In this project, Hillman rubber grommet (1 $1 / 8$ " OD and $5 / 8$ " ID), shown in Fig. 4 is used as damping system for the partition walls. Figure 5 shows details of the damping system installations. The partition walls were constructed as follows:

- The bottom track is bolted to 6 in. thick concrete slab with $1 / 2$ " bolts

- Steel studs were attached to the tracks and spaced at 24 in. The top of the partition wall is free

- Two transverse shoulder walls were connected to both ends of the specimen, but not fasten to the floor slab

- Gypsum sheathing fixed to studs, top track and bottom track with \# 6 screws

- Loading actuator is connected at 4.0 " from the top of the wall

- Cyclic load was set at frequency $0.1 \mathrm{~Hz}$ for 10 cycles

- The loading range from $0.25 "$ to 2.75 " with intervals 0.25 "

- Each wall was instrumented with two LVDT (Linear Variable Differential Transformer) displacement gages to measure vertical displacement, while the MTS machine measures horizontal displacement. All measured data were recorded using MTS 5100 data acquisition device

Table 1. Experimental groups

\begin{tabular}{llll}
\hline Group number & Number of specimens & Specimens & Test type \\
\hline 1 & 3 & $1,2,3$ & No damping test \\
2 & 3 & $4,5,6$ & Single damping test \\
3 & 3 & $7,8,9$ & Double damping test \\
\hline
\end{tabular}

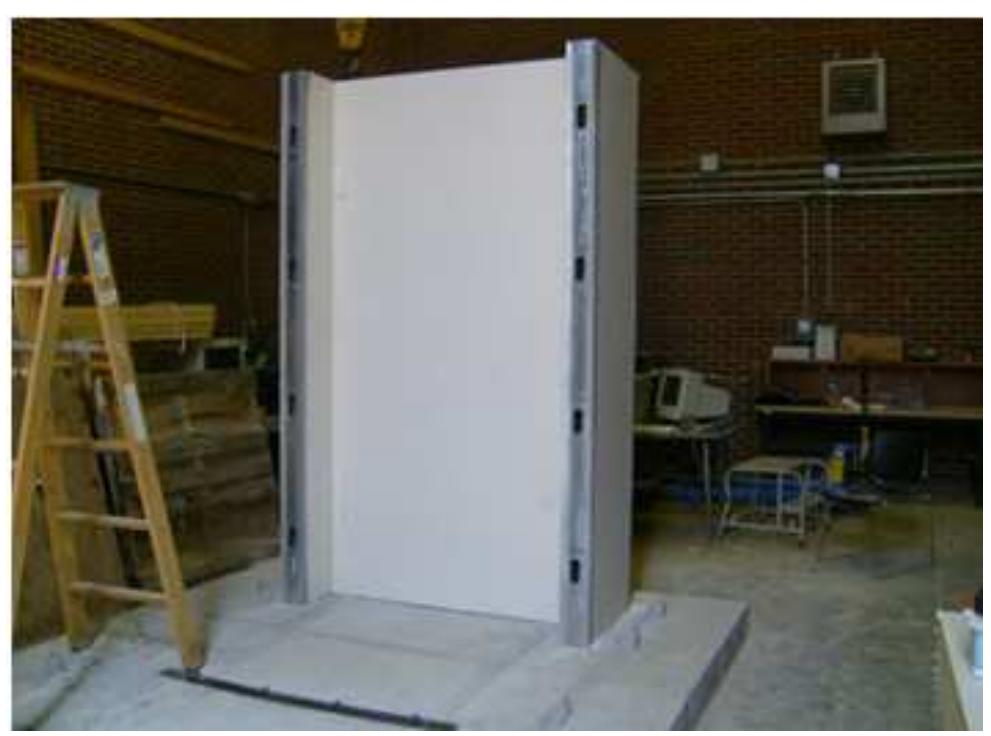

Fig. 3. Constructed partition wall 


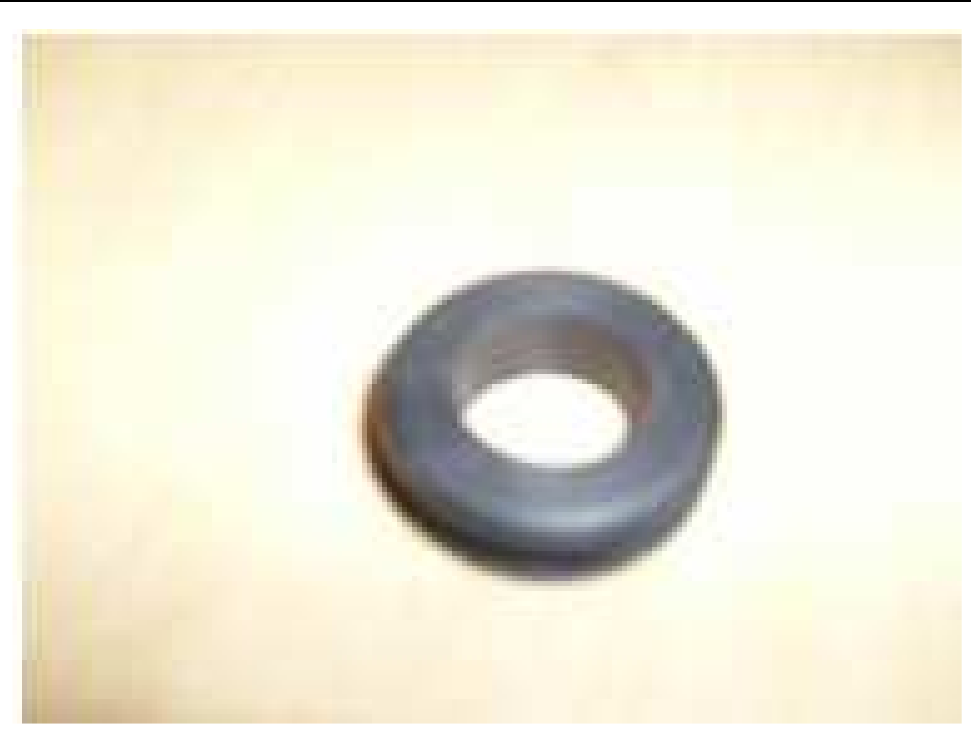

Fig. 4. Damping grommet

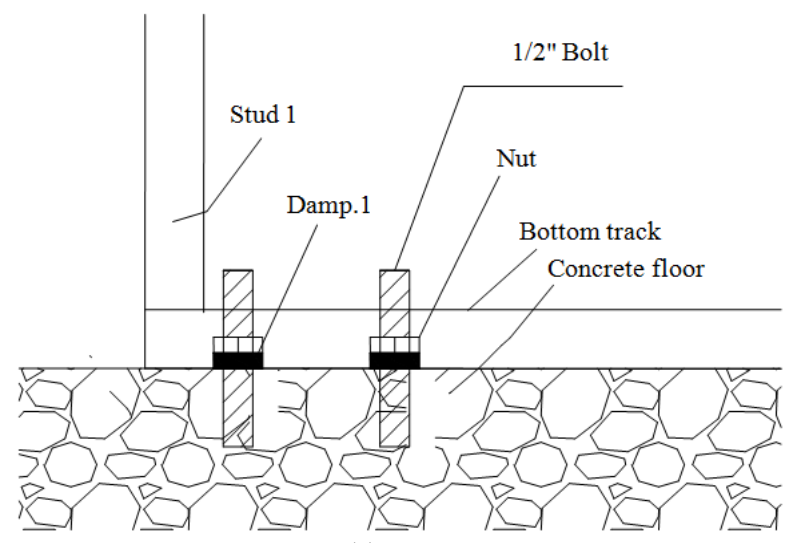

(a)

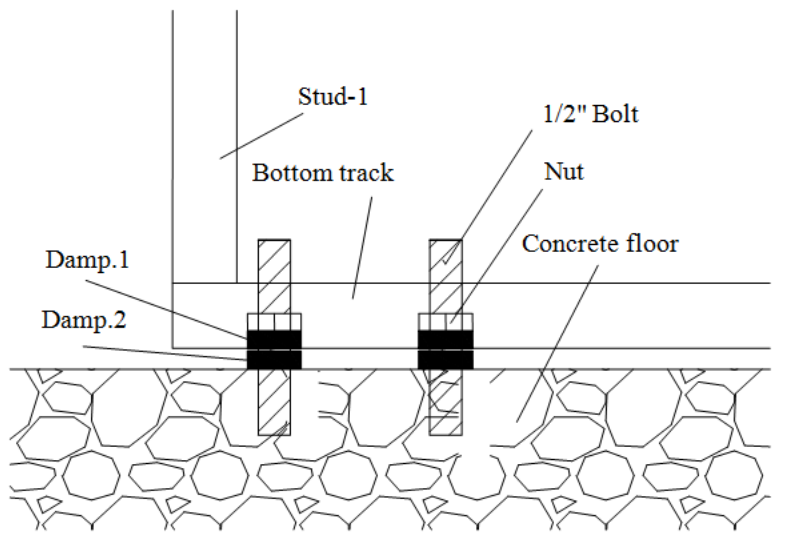

(b)

Fig. 5. Details of the damping systems (a) Single Damping System (SDS) (b) Double Damping System (DDS)

\section{Capacity Validation}

According to ASCE 7-10, the permissible drifts in buildings subjected to wind or seismic loading conditions are usually assumed to be $\mathrm{H} / 400$ for wind loadings and $0.02 * \mathrm{H}$ for seismic loadings, where $\mathrm{H}$ is the height of the wall. Thus, for a wall of $8 \mathrm{ft} \mathrm{high,} \mathrm{the}$ allowable drifts would be $0.24 \mathrm{in}$. for wind loads and 1.92 in. for seismic loadings. In this research project, cyclic loadings were carried out up to a maximum drift of $2.75 \mathrm{in}$. which is about $3 \%$ of the 8 feet height wall. Figure 6-8 show the cyclic peak points envelopes (maximum load of each drift) of the cyclic load-displacement curves for No Damping System (NDS), Single Damping System (SDS) and Double Damping System (DDS) respectively. From these figures, it can be seen that the maximum load capacity is about $850 \mathrm{lb}$ at a displacement of $1.25 \mathrm{in}$. for NDS,
$810 \mathrm{lb}$ at a displacement of $2.0 \mathrm{in}$. for SDS and $875 \mathrm{lb}$ at a displacement of 2.5 in. for DDS. Figure 6-8 also show the permissible drifts corresponding to wind and seismic loadings as well as the ultimate drift and drift corresponding to $75 \%$ of the peak load.

The peak loads and their corresponding drifts values are listed in Table 2. Ductility factor, which may be considered as a measure of ductility for the partition wall, can be defined as the ratio of the ultimate displacement to the displacement corresponding to $75 \%$ of the peak load (yield point) on the rising part of the envelope curve (Lee et al., 2007). Using this definition, we determined ductility factors as listed in Table 2. It can be seen that the ductility factor for specimens with no damping system is 1.93; however it increased about $40 \%$ to 2.7 and $83 \%$ to 3.53 by introducing single damping and double damping systems, respectively. 
Salah Amer et al. / American Journal of Engineering and Applied Sciences 2015, 8 (4): 666.677 DOI: 10.3844/ajeassp.2015.666.677

Table 2. Peak loads, capacities ductility factors

Damping type

Peak load lb.

Drift at Peak load (in.)

Capacity (lb.) at wind drift

Capacity (lb.) at seismic drift 0.92 in.)

Ductility factor

No damping

849.00

1.25

200.00

100.00

1.93
Single damping

809.0

2.0

300.0

800.0

2.7
Double damping

875.00

2.50

300.00

850.00

3.53

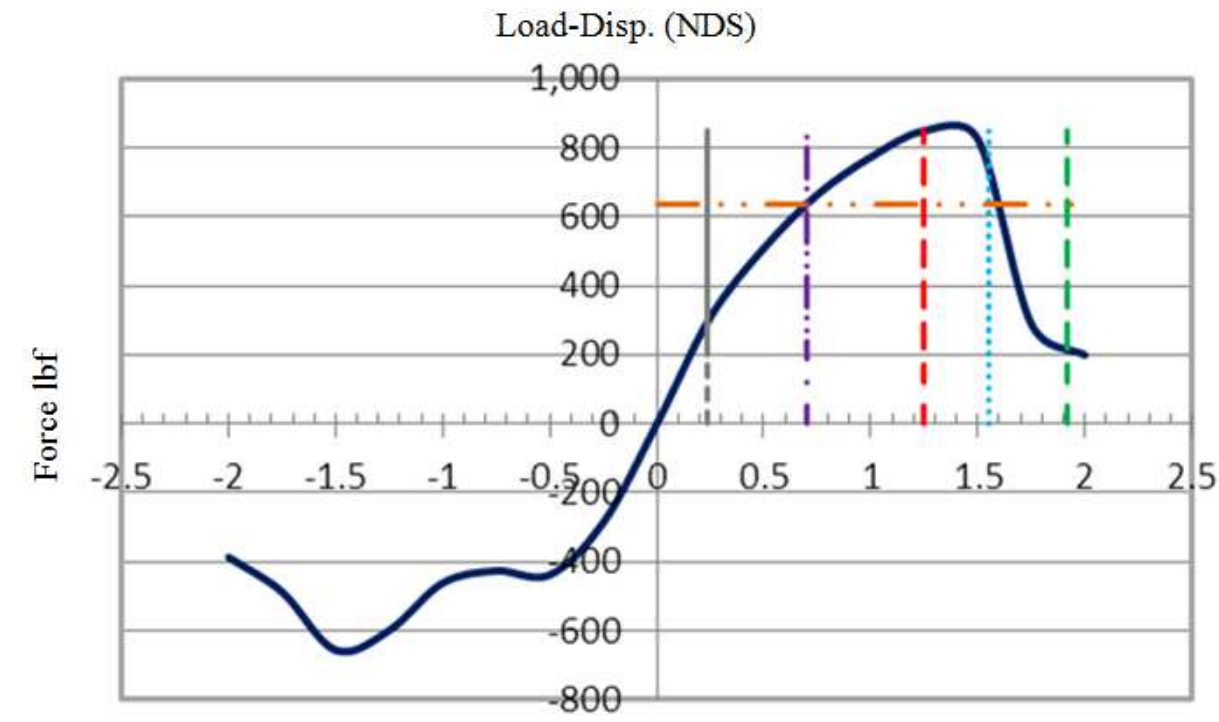

Force $\mathrm{lbf} \quad-\quad-$ Peak drift - - -Seismic drift--- - - Wind drift

Ultimate drift $-\cdots 75 \%$ peak $\quad-.75 \%$ peak drift

Drift (in.)

Fig. 6. Cyclic peak points envelopes for NDS

Load-Disp. (SDS)

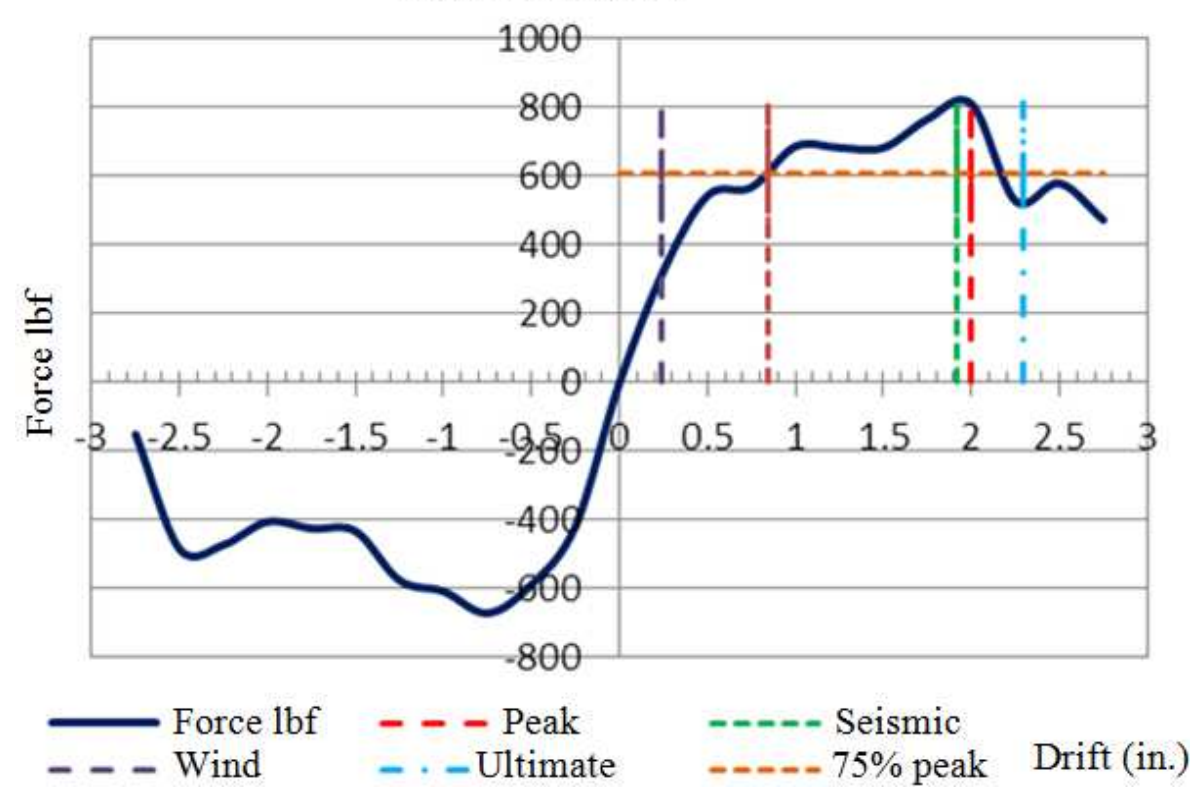

Fig. 7. Cyclic peak points envelopes for SDS 
Load-Disp. (SDS)

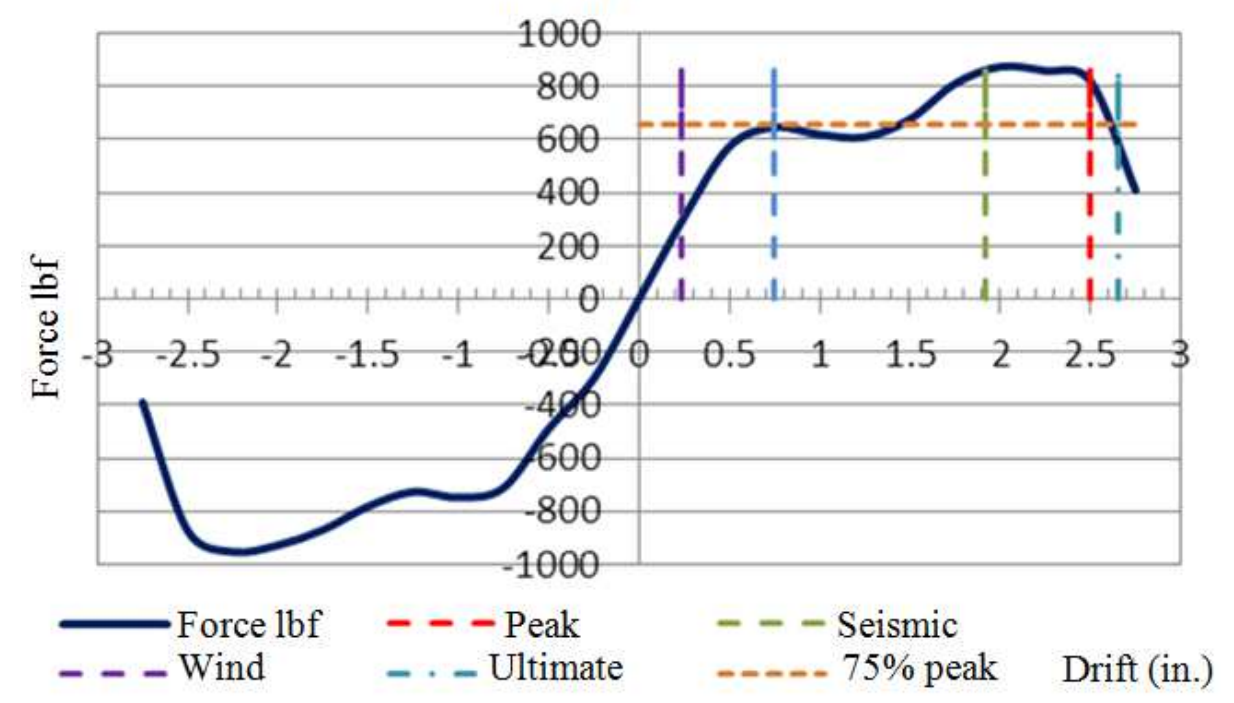

Fig. 8. Cyclic peak points envelopes for DDS

\section{Energy Evaluation}

In order to evaluate the effectiveness of the damping systems, one may need to determine the dissipated energy of each partition wall damping system. The energy dissipated is normally determined by calculating the area under the monotonic load-displacement curve. For cyclic loading, the overall energy dissipated can be determined by the summation of all energies dissipated in each cycle. Researchers (Ali et al., 2008; Filiatrault et al., 2004; Wood and Hutchinson, 2012) calculated the energy dissipated for each half cycle of loading and then accumulated for the total cycles. The mechanical Energy (E) is the work done (W) by the applied Force (F) to move the wall top horizontally in plane distance $(\mathrm{ds}) ; \mathrm{W}=\mathrm{E}=\int$ F.ds. It may be obtained by numerically integrating the area under the load-displacement curve for each half cycle. The process of finding the total energy of each half cycle starts with filtering the whole cycles (Fig. 9) to positive side only of the cycles (Fig. 10). The energy is then calculated for each half cycle by finding the area under the blue solid line in Fig. 11, which is the forward load curve on wall and added to the area under the red dotted line (Fig. 11), which is the back work direction. The total energy is the sum of all cycles for all drifts from 0.25 " to 2.75 ". In this project, the trapezoidal function was found to be in good accuracy to find the area numerically. Matlab software can be used with the function $\mathrm{E}=$ sumtrapz (disp, force) after uploading the displacements and loads as input data to the program. However, in this study, Microsoft excel was used with the trapezoidal function:

$$
E=1 / 2 *\left(y_{1}+y_{2}\right) *\left(x_{2}+x_{1}\right)
$$

where, $y_{1}$ and $y_{2}$ are the force dada and $x_{1}$ and $x_{2}$ are displacement data.

\section{Energy Dissipated for NDS Partition Walls}

Table 3 shows the cumulative energy dissipated at the end of each drift. The total energy dissipated for the NDS wall specimens was $30,482 \mathrm{lb}$ - in at a maximum drift of 2.0 inches. At this drift the wall lost all of its functions and became unstable. Figure 12 also shows the cumulative energy of the NDS walls. It can be seen that the energy function start with low slope up to drift of 0.75 in., followed by linearly increased slope. The energy-drift relationship illustrated in Fig. 13 shows a linear relation up to 1.25 " drift with current drift energy equal to $6,109 \mathrm{lb}-\mathrm{in}$. Then the slope inverted to negative up to 1.6 " drift to start positive again until failure. It should be noted that the 1.25 " drift represents the drift at the peak load of the NDS walls.

\section{Energy Dissipated for SDS Partition Walls}

Table 4 and Fig. 14 show the cumulative energy at different drifts of the SDS top walls. The total energy dissipated was $64,586 \mathrm{lb}$. in or $112 \%$ increase from the NDS case. As shown in Fig. 14, the slope of the energy-drift curve starts with low slope from 0 to 1.25 ", increased up to 2 " drift, then continue sharp increase to failure. The 2" drift represents the drift at the peak load of the SDS walls. Figure 15 shows the individual energy of each current drift. The slope of the curve is positive up to 1.75 " drift to switch to negative slope up to 2.25 " drift then positive again to failure. The change in slope occur just before and just after the drift at the peak load. 


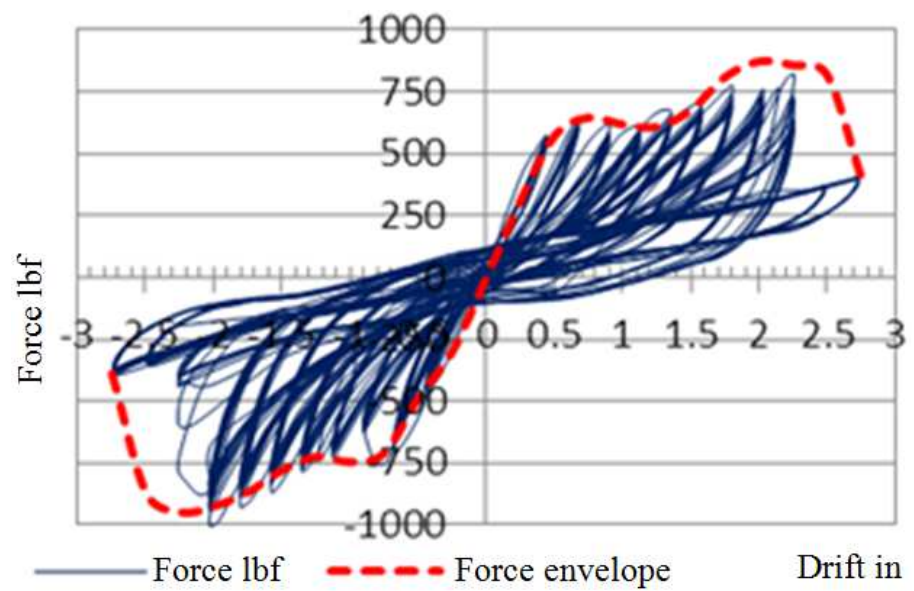

Fig. 9. Cyclic load-drift for 10 cycles

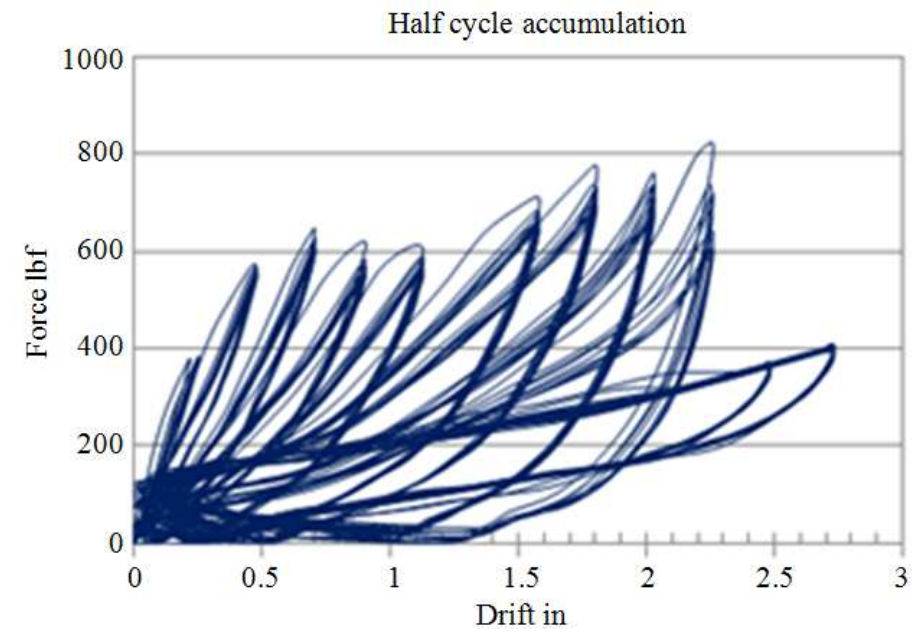

Fig. 10. Cumulative positive sides half cycles

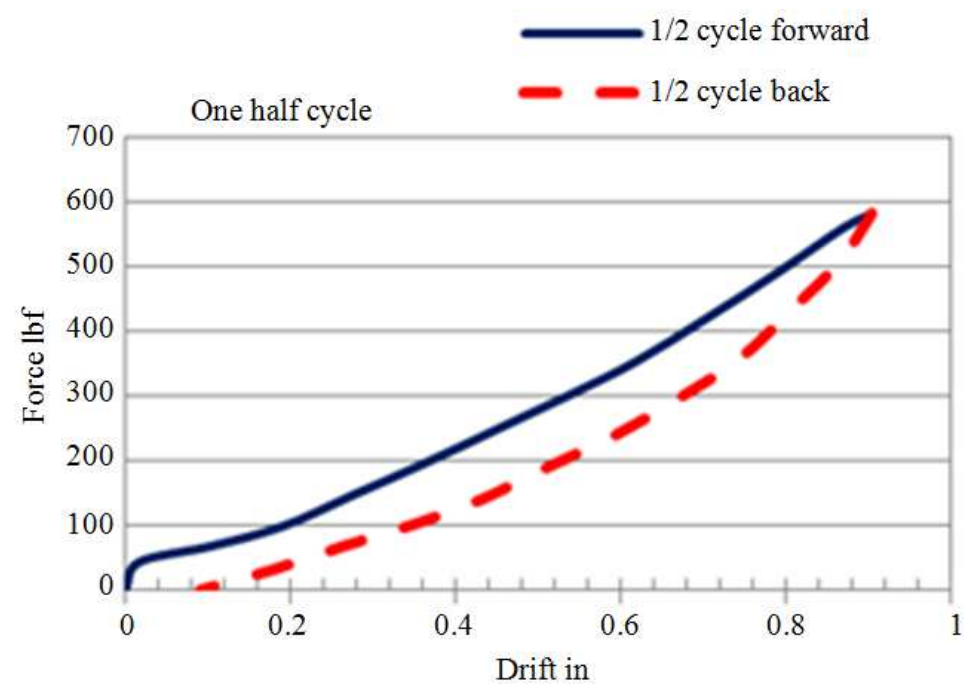

Fig. 11. Half cycle force-drift relationship 


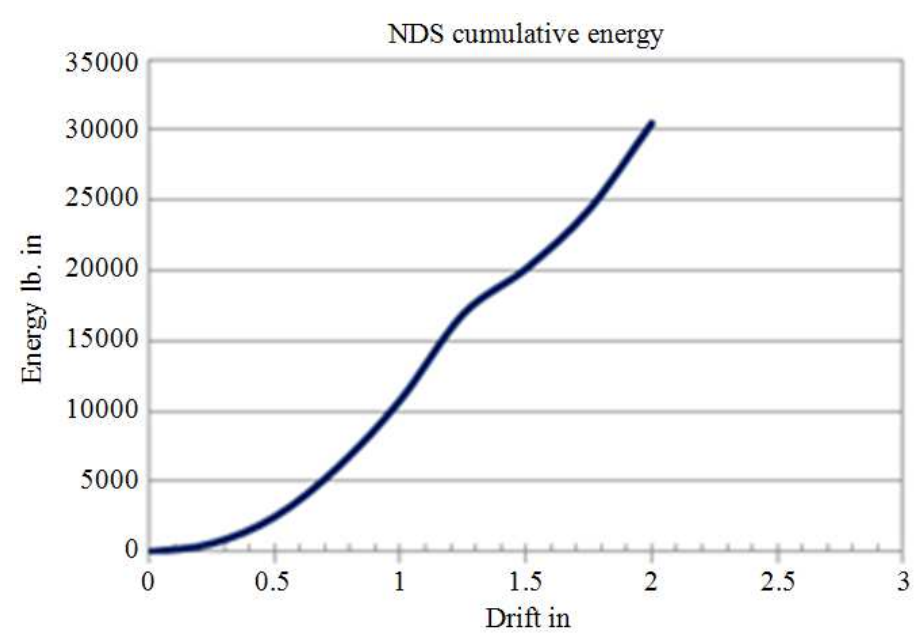

Fig. 12. Cumulative energy dissipated for NDS walls

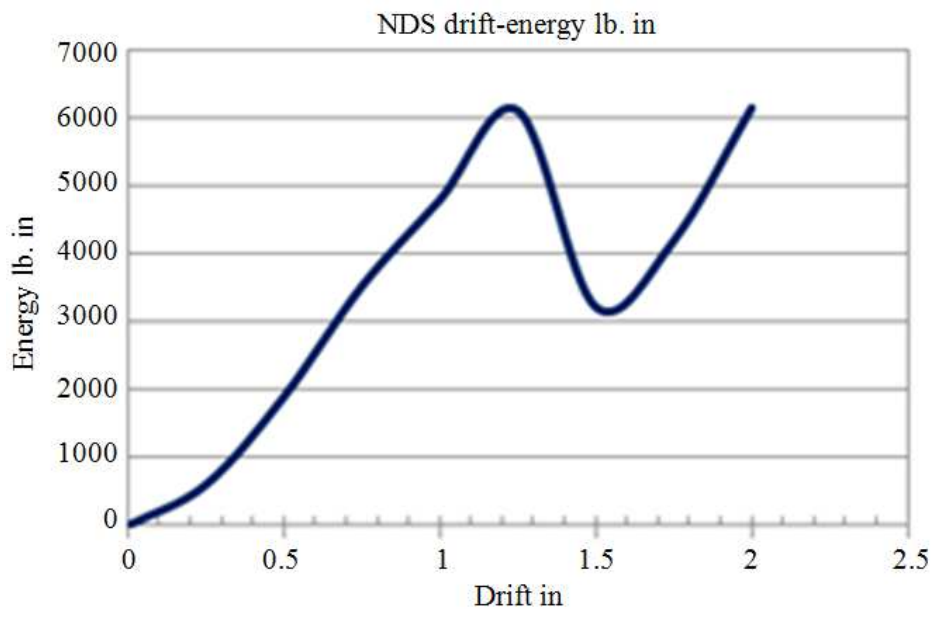

Fig. 13. Energy Vs. drift (NDS walls)

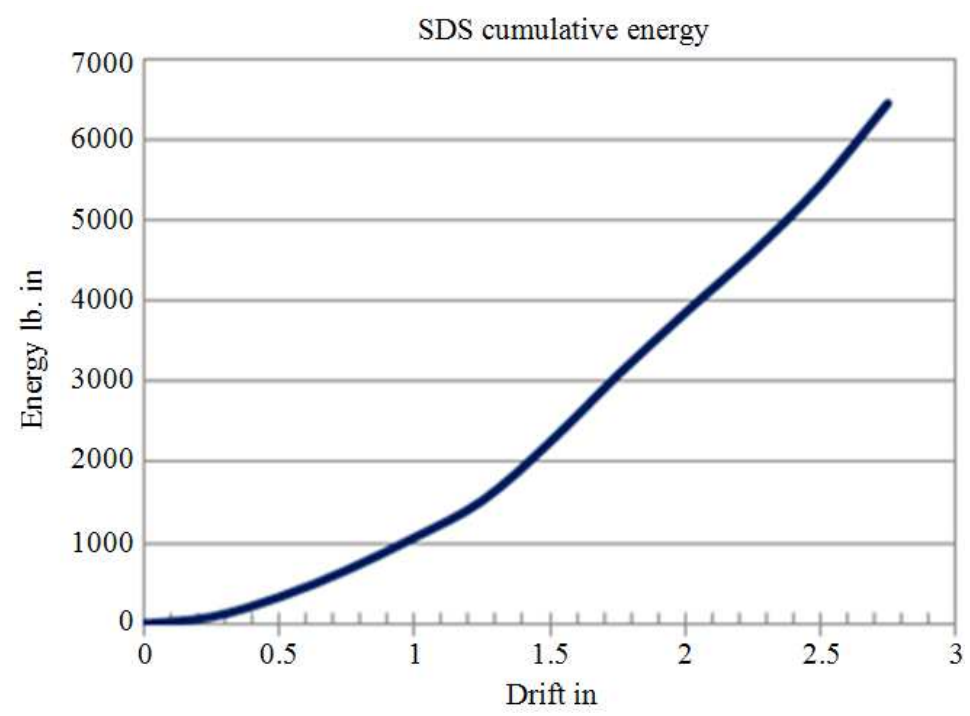

Fig. 14. Cumulative energy dissipated for SDS walls 


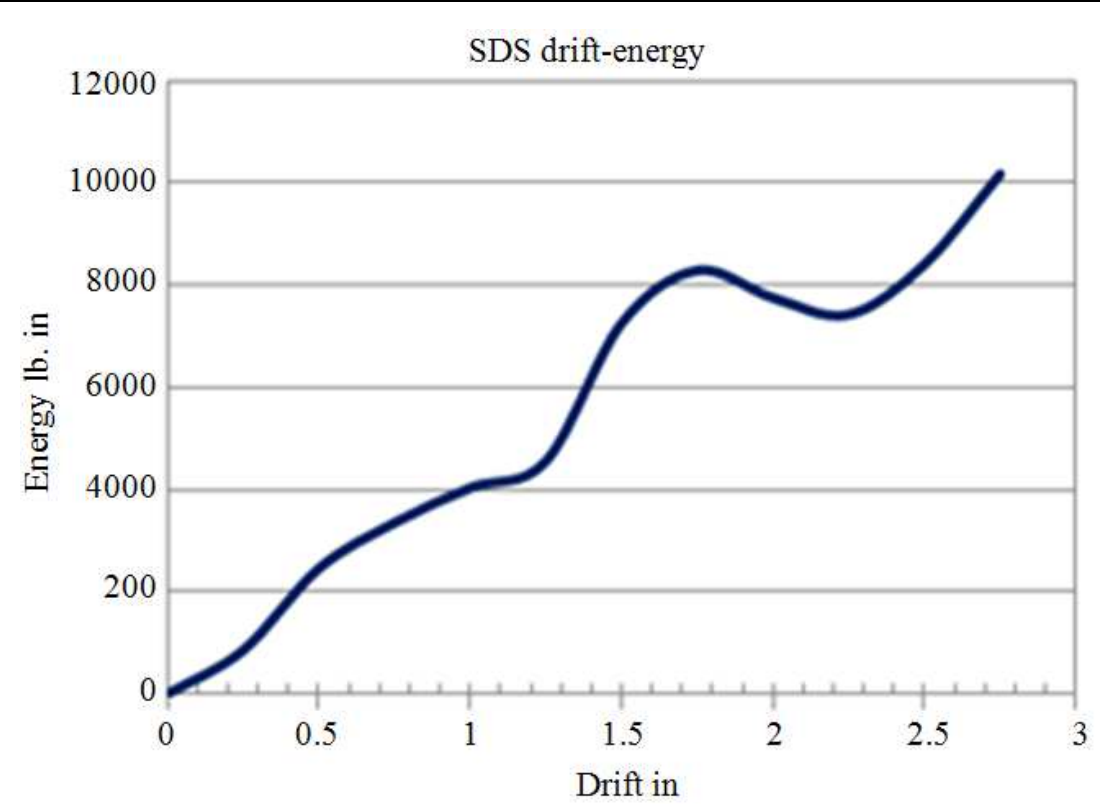

Fig. 15. Energy Vs. drift (SDS walls)

Table 3. Cumulative energy dissipated (NDS walls)

\begin{tabular}{lcr}
\hline Drift (in) & Energy $(\mathrm{lb}-$ in $)$ & Cumulative energy \\
\hline 0.00 & 0.000 & 0.000 \\
0.25 & 602.200 & 602.200 \\
0.50 & 1894.200 & 2496.400 \\
0.75 & 3522.300 & 6018.700 \\
1.00 & 4794.900 & 10813.600 \\
1.25 & 6109.600 & 16923.200 \\
1.50 & 3216.300 & 20139.500 \\
1.75 & 4192.100 & 24331.600 \\
2.00 & 6145.000 & 30481.600 \\
\hline
\end{tabular}

Table 4. Cumulative energy dissipated (NDS walls)

\begin{tabular}{lrr}
\hline Drift (in.) & Energy lb. in & Cumulative energy \\
\hline 0.000 & 0.0 & 0.0 \\
0.250 & 855.1 & 855.1 \\
0.500 & 2456.2 & 3311.3 \\
0.750 & 3353.0 & 6664.3 \\
1.000 & 4036.9 & 10701.2 \\
1.250 & 4559.2 & 15260.4 \\
1.500 & 7261.0 & 22521.4 \\
1.750 & 8291.9 & 30813.3 \\
2.000 & 7753.4 & 38566.7 \\
2.250 & 7429.5 & 45996.2 \\
2.500 & 8410.9 & 54407.1 \\
2.750 & 10179.1 & 64586.2 \\
\hline
\end{tabular}

\section{Energy Dissipated for DDS Partition Walls}

Cumulative energies for the DDS walls are tabulated in Table 5 and illustrated in Fig. 16. The total energy dissipated for DDS was $72,356 \mathrm{lb}$-in or about $137 \%$ increase from NDS walls. $\underline{\text { Table 5. Cumulative energy dissipated (DDS walls) }}$

\begin{tabular}{lrc}
\hline Drift. (in.) & Energy lb. in & Cumulative energy \\
\hline 0.00 & 0.0 & 0.0 \\
0.25 & 715.2 & 715.2 \\
0.50 & 2292.5 & 3007.7 \\
0.75 & 2916.3 & 5924.0 \\
1.00 & 5214.6 & 11138.6 \\
1.25 & 6427.1 & 17565.7 \\
1.50 & 6475.9 & 24041.6 \\
1.75 & 8205.8 & 32247.4 \\
2.00 & 9273.6 & 41521.0 \\
2.25 & 9055.3 & 50576.3 \\
2.50 & 10638.7 & 61215.0 \\
2.75 & 11140.9 & 72355.9 \\
\hline
\end{tabular}

Figure 16 shows relatively low slope up to 1.25 " drift followed by sharp increase. Figure 17 illustrates the relationship between the individual energy and its corresponding current drift. The slope of the curve is positive up to 1.25 " drift (which is the drift at the peak load of the NDS), followed by flat curve up to 1.5 " to positive up to 2 " drift. Then the slope switches to negative until the drift reaches 2.25 " to start positive again. It should be mentioned that the drift at the peak load of the DDS was 2.5". Figure 18 shows a comparison of the cumulative energy dissipated for the three wall systems. The figure, clearly, illustrates the effectiveness and the superiority of the damping systems. As shown, the effect of damping on the energy dissipated starts at drift of 1.0". Below this drift, none of the three wall systems shows any signs of major damage nor a loss of its stiffness. 


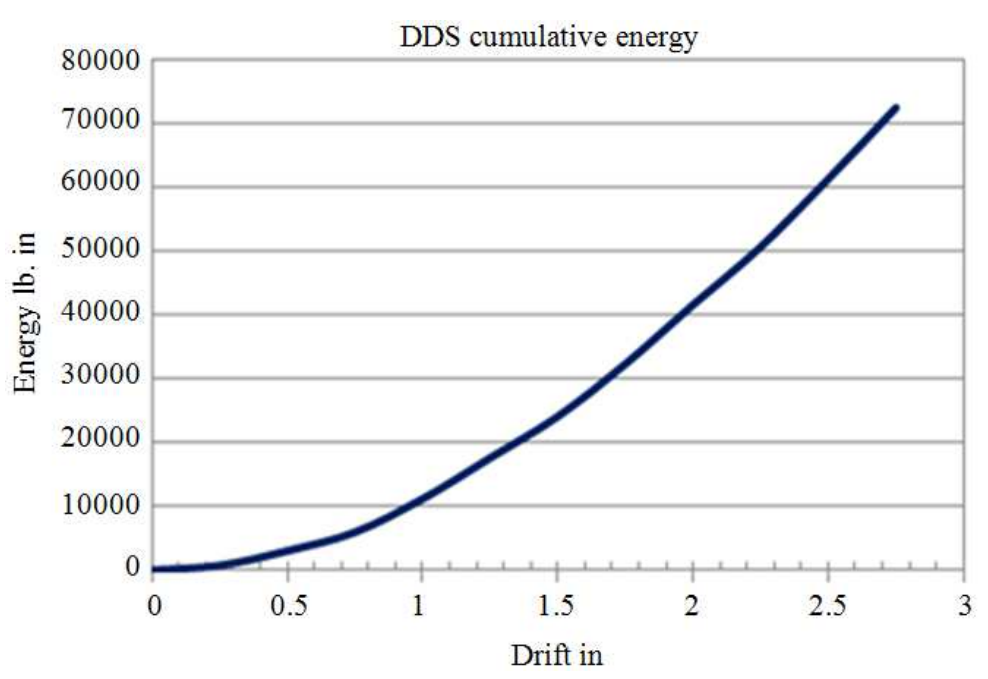

Fig. 16. Cumulative energy dissipated for DDS walls

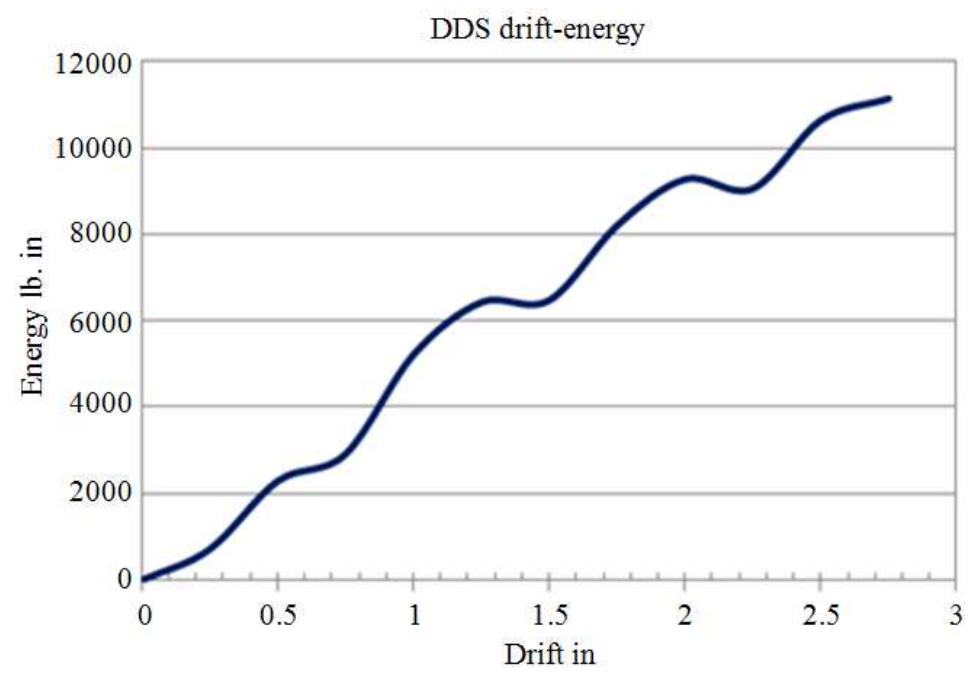

Fig. 17. Energy Vs. drift (DDS walls)

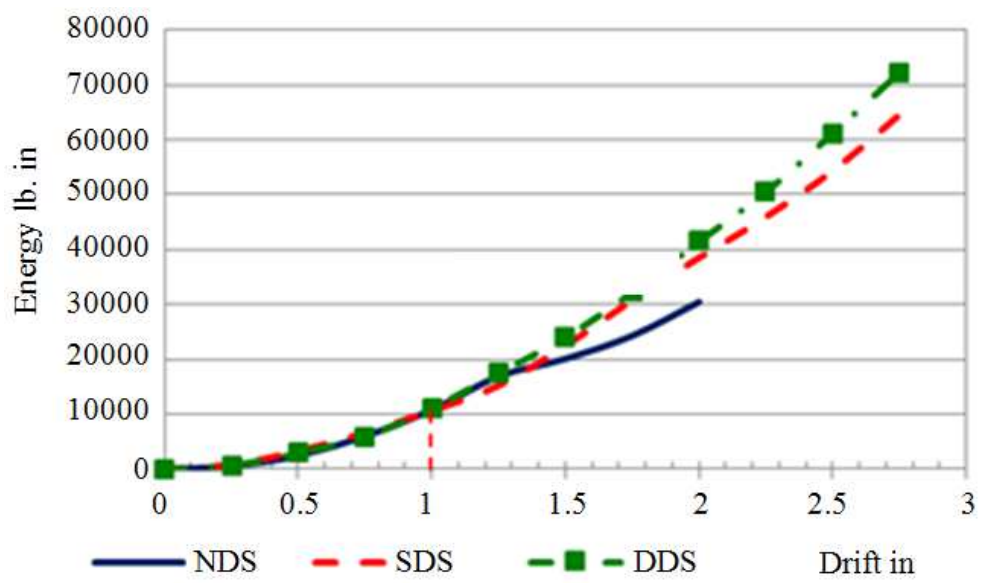

Fig. 18. Cumulative energy dissipated for the three damping systems 


\section{Discussion}

In order to fulfill the objectives of this research project, several data of interest were collected during the cyclic loading tests. This included the applied load and the corresponding displacements at different locations on the wall specimens. Displacements include: Lateral drift at the top of the wall (measured by MTS 5100 data acquisition device), uplift vertical displacement and the slip of the wall at the base (measured by LVDT). The MTS machine was also used to measure the applied load. The loading was applied using the hydraulic powered actuator MTS 100 testing machine of 100 kip capacity. The actuator is connected to control panel where it was set to run cyclic displacement at $0.1 \mathrm{~Hz}$ frequency and return rate of 0.1 " per second. The cyclic loading protocol used was reversed loading for 10 cycles with drift gradually increased from 0.25 " to 2.75 " at 0.25 " increments. Three groups of wall specimens were tested under cyclic loading using this loading protocol and the load-displacement curves were generated using the data recorded for load and displacements by the data acquisition device. After each test, locations and types of damages were identified. The types of failure included chipping of the drywall, crushing at the corners, enlargement of holes' size around drywall screws, brocken screws, hinge formation, etc.

\section{Capacity Validation}

The cyclic peak points envelope, shown in Fig. 6-8, is the maximum load of each drift. Comparison between these figures shows that the maximum load capacity of NDS walls is about $850 \mathrm{lb}$ at a displacement of $1.25 \mathrm{in}$., while the load capacity for SDS is about $810 \mathrm{lb}$ at a displacement of $2.0 \mathrm{in}$. and $875 \mathrm{lb}$ at a displacement of 2.25 in. for DDS. This means that the maximum load capacities for the cyclic loading of the SDS and DDS were about $5 \%$ less and $3 \%$ higher, respectively compared to the NSD walls. However, the displacement at the peak load increased $60 \%$ from 1.25 in. to $2.0 \mathrm{in}$. for the SDS walls and $100 \%$ for the DDS walls. It should be noted that in order to estimate the seismic ultimate strength capacity of the walls, we may average the maximum positive value and the absolute value of the negative cyclic loading curves. In this case, it would be about $785 \mathrm{lb}$ for the NDS walls.

The tested wall specimens were observed for damages at different loading levels. For NDS walls, damages and separation of gypsum board around screws near bottom track occur at 1.25 in. drift. Brocken screws that fasten middle and left studs to bottom track was observed at drift amplitudes of $1.5 \mathrm{in}$. and complete loss of the wall function happen at $2.0 \mathrm{in}$. drift, where hinge formation of the bottom track and crushing at the corners were observed. The most severe damage to drywall screws occurred at the bottom of the wall at end studs. Damages to SDS and DDS wall specimens were similar but occur at later stages of NDS specimens. No damages observed in the upper part of the wall.

\section{Energy Evaluation}

The peak loads of the tested damping systems are tabulated in Table 2 along with the ductility factors and with the permissible drifts due to wind and seismic loading conditions. Table 2 shows that the peak loads of the SDS and DDS wall specimens were reached at relatively higher drift than the permissible values, while the peak loads for the NDS specimens were reached at larger drift than the permissible values for wind loadings but at lower drifts than that for seismic loading. Also, Table 2 shows that the ductility factors for NDS walls was 1.93 but increased about $40 \%$ to 2.7 and $83 \%$ to 3.53 by introducing single damping and double damping systems, respectively.

As aforementioned, the energy dissipated is determined by the area under the load-displacement curve. In this project, the overall energy dissipated was calculated by the accumulation of the energy dissipated in each cycle. If one calculated the area under the envelope curve, it would result in a much smaller value than that of the accumulated value.

\section{Conclusion}

Although, considerable portion of the structural wood and steel frame systems consist of partition wall systems, they normally are not included in the structural design. However, seismic damages to partition walls may result in a huge cost due to their repair/replacement and also due to replacements of damaged contents and devices that resulted from falling partition walls. The goal of this investigation was to experimentally evaluate the effectiveness of using low cost damping protection system in improving the seismic performance of the steel stud partition walls. The experimental program tested nine full scale specimens of $4.0 \mathrm{ft}$ wide and $8.0 \mathrm{ft}$ high. Wall specimens were divided into three systems namely, NDS; SDS; and DDS subjected to in-plane cyclic loadings for drifts ranging from 0.25 " to 2.75 " (0.3 to $3 \%$ drifts). Seismic evaluation includes both ductility capacity and energy dissipation. The following conclusions can be made from the test results of this study:

- Results of the cyclic peak points envelopes show no significant change in the maximum load capacity of the walls when comparing between the three groups. On the other hand, displacement at peak load increased 60 and $100 \%$ with single and double damping respectively, indicating that although damping does not influence strength, it 
improves ductility and delays damages to later drifts. Thus, the maximum damped wall capacities were reached at larger drifts

- Comparing damped systems to no damping, the wind load capacity (at 0.24 " drift) increased by $50 \%$ and the seismic load capacity (at 1.92" drift) increased by $700 \%$

- Comparing SDS and DDS walls to NDS, ductility factors increase by 40 and $83 \%$ respectively

- The cumulated dissipated energy for SDS walls increased by $112 \%$, while for DDS the increase was about $137 \%$

- Proper connections to transfer lateral loads to steel studs are needed

- Overall, the test results show that the low cost protection damping system significantly improved the seismic performance of the partition wall systems

\section{Acknowledgment}

This paper summarizes the findings of a research work supported in part by the National Science Foundation in collaboration with the University of New York at Buffalo (UB). Any findings, conclusions and recommendations expressed in this paper are those of the authors.

\section{Funding Information}

The work reported here was financially supported by the National Science Foundation (NSF) and Network for Earthquake Engineering Simulation (NEES).

\section{Author's Contributions}

Each author of this manuscript made considerable contributions in conducting the experimental testing, data-analysis and contributed to the writing of this manuscript.

\section{Ethics}

The authors would like to disclose that Dr. Taher M. Abu-Lebdeh (Co-author) is a member of the editorial board for the American Journal of Engineering and Applied Sciencs.

\section{References}

Ali, M., B. Kasal, H.B. Manbeck and A.R. Adams, 2008. Eperimental cyclic racking evaluation of light-frame wood stud and steel stud wall systems. The Pennsylvania Housing Research Center.

Dyke, S.J., B.F. Spencer Jr., M.K. Sain and J.D. Carlson, 1996. Modeling and control of magnetorheological dampers for seismic response reduction. Smart Mater. Structures, 5: 565-565.
Filiatrault, A., S. Kuan and R. Tremblay, 2004. Shake table testing of bookcase-partition wall systems. Canadian J. Civil Eng., 31: 664-676. DOI: $10.1139 / 104-031$

Lee, T.H., M. Kato, T. Matsumiya, K. Suita and M. Nakashima, 2007. Seismic performance evaluation of non-structural components: Drywall partitions. Earthquake Eng. Structural Dynam., 36: 367-382. DOI: $10.1002 /$ eqe. 638

Mokha, A., N. Amin, M.C. Constantinou and V. Zayas, 1996. Seismic isolation retrofit of large historic building. J. Structural Eng., 122: 298-308. DOI: 10.1061/(ASCE)0733-9445(1996)122:3(298)

Nagarajaiah, S. and S. Xiaohong, 2000. Response of base-isolated USC hospital building in Northridge earthquake. J. Structural Eng., 126: 1177-1186. DOI: 10.1061/(ASCE)0733-9445(2000)126:10(1177)

Ryan, D.D., R.R. Gilberto and G. Mosqueda, 2011. Simulation of the seismic performance of nonstructural systems. National Seince Foundation.

Singh, M.P., E.E. Matheu and S. Singh, 2000. A response spectrum approach for seismic performance evaluation of actively controlled structures. Earthquake Eng. Structural Dynam., 29: 1029-1051. DOI: $\quad 10.1002 / 1096-9845(200007) 29: 7<1029:: A I D-$ EQE952>3.0.CO;2-O

Whittaker, A.S. and T.T. Soong, 2003. An overview of nonstructural components research at three U.S. earthquake engineering research centers. Proceedings of the Seminar on Seismic Design, Performance and Retrofit of Nonstructural Components in Critical Facilities, (CCF'03).

Wood, R.L. and T.C. Hutchinson, 2012. A numerical model for capturing the in-plane seismic response of interior metal stud partition walls. NEESNonstructural Technical Report. 